\title{
The Importance of Databases in the Reproduction Process of Medical Information
}

\author{
Okan Koc \\ Balikesir University, Balikesir, Turkey \\ E-mail: okankocbby@gmail.com
}

\begin{abstract}
In recent years, the importance of electronic information resources in terms of scientific communication has increased considerably. The fact that electronic information sources deliver the most current information to the user in the fastest way in terms of branches of science leads the researchers in medical and health sciences to these resources. Databases are information and access systems that offer a variety of electronic information sources, both public and custom. These are the structures that undertake the guidance / consulting role of the researchers in the re-production of information. It is an indispensable part of today's libraries and researchers with its advantages such as speed, price and ease of use. It makes it compulsory to think about today's information centers, which are of vital importance in the reproduction of academic knowledge, except traditional processes. At the same time, databeses that constitute the support column of research have an important role in the creation of the future society.

In our study, the importance of databases in the reproduction process of medical information has been mentioned. Nevertheless, an evaluation was carried out on the impact of the use of databases and information technologies in academic studies.
\end{abstract}

Keywords: Medical information, Academic information, Knowledge production, Databases, Medical databases

DOI: $10.7176 / \mathrm{JSTR} / 5-3-13$

\section{Tıbbi Bilginin Yeniden Üretim Sürecinde Veritabanlarının Önemi}

\begin{abstract}
Özet
Son yıllarda elektronik bilgi kaynaklarının bilimsel iletişim açısından önemi oldukça artmıştır. Elektronik bilgi kaynaklarının, bilim dalları açısından en güncel bilgiyi en hızlı şekilde kullanıcıya ulaştırıyor olması tıp ve sağlık bilimlerindeki araştırmacıları bu kaynaklara yöneltmektedir. Veritabanları genel ve özel konulu olmak üzere birçok elektronik bilgi kaynağını bir arada sunan bilgi erişim sistemleridir. Veritabanları, bilginin yeniden üretim aşamasında araştırmacıların rehberlik/ danışmanlık rolünü üstlenen yapılardır. Hız, fiyat ve kullanım kolaylığı gibi avantajları ile günümüz kütüphanelerinin ve araştırmacılarının vazgeçilmez bir parçasıdır. Veritabanları, akademik bilginin yeniden üretilmesinde hayati öneme sahip olup, aynı zamanda, tıp ve sağlık bilimlerindeki araştırmacıların alanlarında güncel kalması ile toplumun tüm kesimi üzerinde doğrudan etkisini göstermektedir. Araştırmamızda tıbbi bilginin yeniden üretim sürecinde veritabanlarının önemine değinilmiştir. Bununla birlikte, veritabanlarının ve bilgi teknolojilerinin akademik çalışmalardaki kullanımının etkisi üzerine yönelik bir değerlendirme gerçekleştirilmiştir.
\end{abstract}

Anahtar kelimeler: Tıbbi bilgi, Akademik bilgi, Bilgi üretimi, Veritabanları Tıp veritabanları

\section{Giriş}

Biyolog Julian Huxley, "İnsanın, bilinen yazılı tarih süresi içinde geçirdiği evrim, insan öncesi evrimden yüz bin kere hızlıdır," demektedir. Huxley'in dediğine göre, Taş Devri’nde elli bin yıl alan ve çağı simgeleyen gelişmeler, zamanımızda, uygarlıkların yerleşmesiyle yüz yıllık süreler içinde oluşmaya başlamıştır. Değişimin hızı son beş bin yıl içinde artmıştır. Biyoloğun sözleriyle bu artış, "özellikle son üç yüz yıl içinde belirgindir." (Toffler,2006:38). 
İnsanlık tarihinin son elli bin yılı yaklaşık altmış iki yıllık yaşam sürelerine bölünse sekiz yüz yaşam süresi geçirildiği ortaya çıkar. Sekiz yüz yaşam süresinin altı yüz ellisi mağaralarda geçmiştir (Toffler, 2011,s.28). Ancak son yetmiş yaşam süresi boyunca insanoğlu deneyimlerini gelecek kuşaklara iletme olanağı bulmuştur. Büyük insan kitlelerinin basılı sözcükleri görebilmeleri ancak son altı yaşam süresi içinde gerçekleşmiştir. Zamanı kesinlikle ölçmek olanağı son dört yaşam süresinde sağlanmıştır. Elektrik motorunun her yerde kullanılabilmesi son iki yaşam süresinde söz konusu olmuştur (Toffler, 2006: 28). Son bir yaşam süresi ise teknolojinin hayatımızı devr aldığı yıllardır. Bu yıllarda ortaya çıkan, dijital kültür adı verilen dönem bireyin yaşamına insanlık tarihinin hiç bir döneminde olmadığı kadar sirayet etmektedir.

Bilim ve teknolojideki gelişmelere paralel olarak, bilgi erişim sistemleri gelişimi de hayatımızdaki yerini ve çeşitliliğini artırmıştır. Hızlı bir şekilde artan ve kontrolü zorlaşan bilginin, belirli bir amaç doğrultusunda elde dilmesi ve yararlanılabilecek hale getirilmesi oldukça önemlidir. Akademik bilginin üretilmesi noktasında adı geçen bilginin kontrolünde kütüphanelerin, bilgi merkezlerinin, bilgi sistemlerinin ve veritabanlarının önemli bir rolü vardır.

\subsection{Akademik Bilgi Üretimi}

Günümüzde düşünceyle uygulama arasındaki gecikme hemen hemen düşünülemez. Bunun nedeni çok istekli ya da atalarımızdan daha çalışkan olmamamız değildir. Süreci hızlandıracak tüm sosyal gereçleri bulmuş, sağlamış olmamızdır. Frank Lyun, yüzyılın başından bu yana önemli bir bilimsel buluşun, yararlı teknolojik bir biçime dönüştürülmesi için gerekli sürenin yüzde altmış azaldığını saptamıştır (Toffler,2006:44).

Bilgi erişim sistemlerinin hayatımızda yer almaya başladığı evrelerin temelleri İkinci Dünya Savaşı sonrası dönemde gerçekleşen rekabet ortamıyla paralellik göstermektedir. Sanayi devriminin yerini alan bilgi ve iletişim teknolojilerinin geliştiği yeni dönem 1970'li yıllardan itibaren araştırmacıların dikkatini çekmiştir. Birçok ülkede sanayi toplumun egemenliği ve yaygınlaşma trendinin bu döneme kadar devam ettiği görülmektedir. Dünyanın her yerindeki ülkeler sanayi çağını daha kucaklayamamışken, ileri seviyedeki bilgi ve iletişim teknolojilerine sahip olan ülkelerde yeni süreçlerin başladığı görülmektedir. Bir yanda Sovyetler, diğer tarafta ABD silahlanma ve ekonomi yarışını tetiklerken, ekonomik anlamdaki büyüme ve rekabet yeni bir dönemin kapılarını aralamıştır. Bilgi ve iletişim teknolojilerindeki gelişmeler bu yeni dönemin en büyük özelliğini oluşturmuştur. Bir yandan bu yeniçağın uzay çağı olacağı düşünülürken, diğer taraftan yaşanan birçok gelişme toplumsal anlamda büyük değişiklikleri doğurmuştur. İçinde yaşadığımız toplumun adına her ne denilirse denilsin, nasıl tanımlanırsa tanımlansın, bilgi en büyük güç olma konumunu güçlendirmektedir. Bu süreç göstermektedir ki dünya, tarım ve sanayi devrimi gibi insanlık tarihinde derin toplumsal dönüşümler yaratan bir sürecin daha içerisinde ilerlemektedir (Atasoy, 2007:164).

Bugün akademik bilginin üretim serüvenin de gelinen nokta, yüzyıllardır geleneksel yöntemlerle üretilen kitap, dergi ve diğer çalışmaların artık basım ve yayım teknolojilerinin sağladığı kolaylıklarla kağıt üzerinden elektronik/ dijital ortamlara aktarımı yönünde seyir göstermektedir. Elektronik ortamda üretilen ve erişime sunulan dijital koleksiyonlar, e-kitap, e-dergi, e-makale, e-tez ve diğer şekillerde veri tabanları üzerinde yer almaktadır. Veri tabanı üzerinden bilimsel dokümanlara erişim olanağını kullanıcılarına sunan kütüphaneler önemli bir role sahiptir. Bilgi ve iletişim teknolojilerinin kütüphane hizmetlerinde yarattı̆̆ değişimler sayesinde öncelikle bilgi erişimde yardımcı olan ikincil kaynakların elektronik versiyonları hizmete sunulmuş, bunu diğer bilgi kaynakları izlemiştir. $\mathrm{Bu}$ teknolojilerin kullanılmaya başlanması tüm disiplinlerdeki kullanıcıların bilgi erişimde edindikleri alışkanlıkların değişimine neden olmuştur (Tanrıkulu,2006:3).

Akademik bilginin üretimini, bilim insanlarının herhangi bir konuda mevcut durumu ortaya koymak için cevabını aradıkları ilk soruyla başlatmak mümkündür. Akabinde gerçekleştirilen araştırmaya ait sonucu ve bulguların sözlü ya da yazılı olarak sunulması da bu sürecin içine dahil edilmektedir.

Günümüzde artan teknolojik faaliyetlerin etkisiyle birlikte akademik bilginin üretimi de farklı bir mecraya doğru kaymaktadır. Yaratılan her bilgi bir öncekinin üzerinde yükselmekte, bir öncekinin yerini almakta veya bir öncekine alternatif üretmektedir. Bu üretim sürecinin başından sonuna en temel sütununu doğal olarak kütüphaneler ve onların sağladığı hizmetler teşkil etmektedir. Her akademik çalışmanın yararlandığı, mevcut durumu ortaya koyarken analizlerine güvendiği bilgi kaynakları ilgili literatür içerinde yer alırken, bu bilgi kaynaklarının türlerine göre çeşitliği içerisinde makalelerin önemli bir yeri vardır.

Bilimsel iletişim noktasında gerçekleşen değişimin pek çok faktörü söz konusudur. Bu belirleyici faktörlerin başında, elektronik bilgi ve iletişim teknolojilerinin bilimsel iletişime getirdiği yeni yaklaşımlar dikkat çekicidir. Bu nedenlerden ötürü son dönemde elektronik ortamdaki bilgi kaynaklarına yapılan atıflar çeşitli araştırmalara konu olmaktadır. Kushkowski bir araştırmasında her yıl elektronik kaynaklara yapılan atıf sayısının arttığını belirtirken, basılı ve elektronik web kaynaklarına yapılan atıf oranlarını incelemiş, basılı tezlerdeki atıf oranını $\% 2,2$, elektronik tezlerdeki atıf oranını ise $\% 5,4$ olarak tespit etmiştir (2005). 
Günümüzde bilimsel iletişim açısından webin etkisi her geçen artmaktadır. Davis ve Cohen'in gerçekleştirmiş olduğu çalışma 1996 yılındaki lisans düzeyindeki araştırma raporlarında \%9 olarak tespit edilen web kaynaklarına atıf oranının, 1999'a gelindiğinde \%21 e yükseldiği belirlemiştir (2001,s.309). 2008 yılında yapılan bir diğer çalışma web kaynaklarının bilimsel iletişim açısından önemi vurgular niteliktedir. İlgili araştırma kütüphane ve bilgi bilimlerindeki dokuz derginin kaynakçalarını ele almıştır. Çalışmada 1277 makaleden 1035'inin kaynakçasında web kaynaklarına atıf yapıldığı, yapılan atıfların basılı yayınlara yapılan atıf sayısıyla paralellik gösterdiği tespit edilmiştir (Bhat ve Kumar).

Bununla birlikte, web ortamındaki kullanımı belirleyebilmek adına geliştirilen Counter Projesi kullanım ölçümünde standartlaşmayı sağlarken, araştırmacının herhangi bir konuda yapmış olduğu taramayı, görüntülemeyi ya da indirmeyi kayıt altına almaktadır. Bu durum, araştırmacıların hangi elektronik kaynakları ya da veritabanlarını tercih ettiğini, hangi formatta görüntüleme yaptığını, hangi sayfa türlerini daha kullanılabilir bulduğunu belirlemeye imkan sağlamaktadır. Unutulmaması gereken Counter Projesi kullanıcı ve kaynak bazlı istatistikleri bize sağlayabilirken, bu verileri kullanarak genelleme yapmanın, değişen kullanıcı eğilimlerini belirlemenin yeterli olmadığıdır. Buradan hareketle asıl önemli olan, kullanıcı araştırmaları yaparak, araştırmacıların, tutum, davranış ve tercihlerinin belirlenmesidir (Voorbij ve Ongering, 2006, s. 223).

\subsection{Bilgi Erişim Sistemleri}

Bilgi erişim sistemleri, yalnızca bilgiyi bünyesinde barındırmakla yetinmeyip, bilginin yeniden üretim aşamasında araştırmacıya rehberlik ve destek sağlayan sistemlerdir. Adı geçen temel özelliği araştırmacı ile bilgiyi buluşturuyor olmalarıdır.

Bilginin döngüsü içerisinde kütüphaneler bilgi erişim sistemlerini ayrıca bünyesinde barındırıyor olması sebebiyle art1 bir öneme sahiptir. Kütüphaneler ve bilgi merkezleri bilgi üretimi sürecinde değer yaratan unsurları, enformasyon zincirinin halkalarında rol alan aktörleri, 'yazarlar/araştırıcılar/bilim insanları' ve dolayısıyla ürettikleri bilgi kaynaklarını, 'yayınevlerini', 'dağıtıcı kuruluşları', ve veritabanlarını bir araya getiren bir yapıya sahiptir. (Tamdoğan,2009:152).

Enformasyon zincirinin temel aktörlerine günümüzde eklenen bilgi erişim sistemi türleri arasında yer alan veritabanları ve tarama motorları, kütüphane kurumu ve diğer bilgi merkezleri bünyesinde firsat eşitliği çerçevesinde her bireyin bilgi gereksinimi karşılamak üzere sunulmaktadır. Aynı zamanda bilgi erişim sistemlerini etkili biçimde kullanabilmeleri için araştırmacılara rehberlik etmekte ve eğitim programları (kütüphane okuryazarlığı, Internet okuryazarlığı, enformasyon okuryazarlığı gibi) düzenlemektedir. Kütüphaneler elektronik ortamda yer alan bilgiye erişimde, birey, topluluk ya da toplum arasındaki ayırımı betimleyen 'sayısal ve/veya bilgi uçurumu’ (digitaldivide) olgusunun yaşanmaması yönünde önemli bir toplumsal sorumluluğu yerine getirmektedir (Tamdoğan,2009:156).

Bugün akademik bilginin yeniden üretim serüveninde dikkat çekici olan kullanıcıların en kısa sürede, en doğru ve güncel bilgiye erişim isteğinin belirleyici faktör olmasıdır. Bilgi tarihin her döneminde güç olarak ele alınmış, korunmuş yere ve zamana bağlı olarak değişiklik göstererek paylaşılmıştır, ancak hiç bu kadar hızlı tüketilmemiştir. Hızlı tüketim akabinde teknolojinin de katkısı ile hızlı üretimi de tetiklemektedir. Bilim adamının ve araştırmacıların bu denli hızlı üretim ve tüketim döngüsü içerisine girmesinin birçok farklı sebebi vardır. Kullanıcının bilgi arama davranışını belirleyen bu olguyu Zipf 1949 yılında geliştirdiği “en az çaba kuramı”na göre açıklamıştır.

Bilgi teknolojilerinde yaşanan hızlı değişimlerle birlikte bu bilgi arama davranışı da evrim geçirmekte, sözlü iletişim yolu varlığını sürdürmekle birlikte elektronik bilgi teknolojilerinin ve bilgi erişim sistemlerinin önemi artmaktadır.

Bilgi teknolojilerinin kullanıcıların bilgi arama davranışlarına etkisini belirlemek üzere yapılan araştırmalar, öncelikle kullanıcı grubunun genel özelliklerinin belirlenmesi ve kullanıcıların bilgi kaynaklarını kullanma özelliklerinin anlaşılabilmesi için sadece nicel yöntemle çalışılmıştır. Bu tür çalışmalar, kullanıcıların bilgi teknolojilerini kullanmaları hakkında bilgi sağlamakla birlikte, kullanıcıların sadece bilgi merkezlerinden kaynak sağlama özelliklerini öğrenmeye imkan veren "sistem merkezli” çalışmaların ötesine geçememiştir

Bilgi erişim sistemlerinin akademik bilginin üretim aşamasındaki desteğini 1970'li yıllara değin götürmek mümkündür. 1970'lerde çevrimiçi bibliyografik tarama adaptasyonun incelendiği bir araştırmada, bilgisayar tabanlı bilgi erişimin gittikçe yaygınlaştığı, veritabanı ve çevrimiçi tarama sayısını \% 75 arttığı görülmüştür (Bayer ve Jahoda,1981:).

1993 yllında İngiltere'de “'”ing's College Information Access” projesi kapsamında yürütülen bir araştırmada, bilgi teknolojileri destekli bilgi sistemlerinin kullanımı araştırılmış ve bilgi teknolojilerinin akademik çalışmalardaki bilgi kullanımına etkisi incelenmiştir. Buna göre akademisyenlerin,

- Bilgi teknolojileri destekli bilgi sistemlerini dünyadaki herhangi bir kütüphane kataloğunu taramak,

- Kendi kütüphanelerinin kütüphaneler arası ödünç verme hizmetinden yararlanmak ve reserve materyal isteği yapmak,

101 | $\mathrm{P}$ a g e

www.iiste.org 
- CD_ROM ve çevrimiçi veritabanlarında tarama yaparak ilgili makalelere ulaşmak,

- Önbası ve elektronik dergileri taramak,

- Çevrimiçi veritabanlarında bazı dergileri gözden geçirmek,

- Çevrimiçi atıf indeksleri ile ilgili çalışmaları belirlemek,

- İnternette tartışma gruplarına ve ortak ilgi topluluklarına katılmak,

- Elektronik konferanslara katılmak ve konferans bildirilerine erişmek,

- İnternette tarama yapmak ve dünya çapında bilgiye erişmek amaçlarıyla kullandıkları görülmüştür (Barry, 1995:107-108).

Ayrıca akademisyenlerin, bilimsel çalışmalarda kullandıkları kaynak türleri ve kullanma oranları da Tablo 1'deki gerçekleşmektedir.

Tablo 1. Akademisyenlerin bilimsel çalışmalarda kullandıkları kaynak türleri ve kullanım oranları ( Jankowska,2004,s.60).

\begin{tabular}{|c|l|c|}
\hline \multirow{4}{*}{ Araştırma } & Kaynak Türü & Kullanım Oaranı (\%) \\
\cline { 2 - 3 } & Tam metin makaleler/ kitaplar & 84 \\
\cline { 2 - 3 } & Çevrimiçi veritabanları & 80 \\
\cline { 2 - 3 } & Resmi belgeler & 52 \\
\cline { 2 - 3 } & Konferans bildirileri & 47 \\
\cline { 2 - 3 } & Özel kurum/kuruluş web sayfaları & 45 \\
\cline { 2 - 3 } & Dijital arşivler & 41 \\
\cline { 2 - 3 } & Elektronik danışma kaynakları & 33 \\
\cline { 2 - 3 } & Ödül ve araştırma fonu kaynakları & 13 \\
\hline \multirow{5}{*}{ Ĕgitim } & Uzaktan eğitim paketleri & 33 \\
\cline { 2 - 3 } & Sanal eğitim araçları & 27 \\
\cline { 2 - 3 } & Yeni bası ve ders notları & 26 \\
\cline { 2 - 3 } & Raporlar, haber hizmetleri & 21 \\
\cline { 2 - 3 } & Diğer elektronik kaynaklar & 12 \\
\hline
\end{tabular}

2004 yılında Jankowska tarafindan yapılan araştırmaya göre elektronik ortamdaki bilgi kaynaklarının kullanım oranı özellikle veritabanları açısından oldukça yüksektir. Bilimsel araştırmalarda veritabanı kullanımı \%80, web sayfası kullanımı \% 45 ve elektronik danışma kaynağı kullanımı ise \%33 olarak belirlenmiştir. Yine aynı araştırmaya göre, bilim insanlarının \% 33'ü uzaktan online eğitim paketlerini tercih etmektedir.

Ülkemizde yapılan bir araştırmaya göre akademisyenlerin internet kullanımlarına ilişkin bilgilere ulaşılmıştır (Yayl1, Öztürk ve Alabay, 2003: 11). 
Tablo 2. Akademisyenlerin internet kullanımlarına ilişkin bilgiler.

\begin{tabular}{|c|c|c|c|}
\hline İnternet Kullanıma İlișkin Bilgiler & Frekans & $\%$ & $\mathbf{n}$ \\
\hline İnternete Ulaşım & & & \multirow{7}{*}{414} \\
\hline Evden & 270 & 65,2 & \\
\hline Üniversiteden & 393 & 94,9 & \\
\hline Arkadaşlardan & 15 & 3,6 & \\
\hline Diğer resmi kurumlardan & 15 & 3,6 & \\
\hline İnternet cafelerden & 60 & 14,5 & \\
\hline Diğer özel kurumlardan & 15 & 3,6 & \\
\hline \multicolumn{3}{|l|}{ İnterneti Kullanım Sıklığı } & \multirow{6}{*}{414} \\
\hline Her gün & 264 & 64,2 & \\
\hline Yaklaşık her gün & 99 & 24,1 & \\
\hline Haftada birkaç gün & 39 & 9,5 & \\
\hline Ayda birkaç gün & 9 & 2,2 & \\
\hline Yılda birkaç gün ve daha az & 0 & 0,0 & \\
\hline \multicolumn{3}{|l|}{ İnterneti kullanım süresi } & \multirow{5}{*}{414} \\
\hline Bir yıldan az & 12 & 2,9 & \\
\hline $1-3$ yil & 150 & 36,2 & \\
\hline $4-6$ yil & 177 & 42,8 & \\
\hline 7 yildan fazla & 75 & 18,1 & \\
\hline \multicolumn{3}{|l|}{ İnterneti kullanım amacı } & \multirow{4}{*}{414} \\
\hline Bilimsel amaçlı & 273 & 65,9 & \\
\hline Genel amaçlı & 135 & 32,6 & \\
\hline Eğlence amaçli & 6 & 1,4 & \\
\hline \multicolumn{3}{|l|}{ Bilgiye ulaşmada kullanılan yollar } & \multirow{4}{*}{414} \\
\hline Arama motorları (yahoo, google, netbul vb.) & 396 & 95,6 & \\
\hline Online veritabanları (Science direct, ebscohost vb.) & 294 & 71,0 & \\
\hline Kitap, dergi, gazete TV vb. & 159 & 38,4 & \\
\hline
\end{tabular}

Tabloya göre akademisyenlerin bilgiye erişimde bilgi erişim sistemleri arasında yer alan arama motorları (google, yahoo, netbul vb.) ve veritabanlarını oldukça yüksek bir oranda kullandıkları tespit edilmiştir. Buradan hareketle akademik bilginin yeniden üretim serüveninde bilgi erişim sitemlerinin etkisinin olduğunu söyleyebiliriz.

2002 yılında tıp fakültesi akademisyenlerinin interneti hangi amaçla kullandıklarını ölçebilmek adına gerçekleştirilen bir çalışmada, araştırmaya katılan 2200 akademisyenin '80'i literatür taraması yaparken, elektronik dergilere erişirken, tıp alanındaki bilgilere ve hasta bilgilerini erişirken interneti kullandıklarını belirtmişlerdir (Casebeer, Bennet, Kristofco, Carillo ve Centor, 2002, s.36).

Ülkemizde 2002 yılında gerçekleştirilen bir diğer araştırmada örnekleme katılan akademisyenlerin \%54,5'i interneti literatür taraması yapmak için kullandığını belirtmiştir (Yılmaz,2002,s.64).

Bilgi ve iletişim teknolojilerindeki gelişim, akademik bilginin üretiminde kolaylık sağlayıp, ona hız kazandırmıştır. Diğer taraftan hızlı bir artış gösteren bilgi dünyasında insanlık doğru ve güvenilir bilgiyi bulmakta bu kadar zorlanmaktadır. Tarihin birçok döneminde olduğu gibi, günümüzün ve geleceğin güçlü toplumlarının da bilgi üzerinde yükseleceği düşünülmektedir. Böyle bir sistem içerisinde araştırmacılar bilgiye erişimde, arama motorları, veri tabanları, online kütüphane katalogları gibi bilgi erişim sistemlerine ve araçlara gereksinim duymaktadirlar.

\section{Veritabanları}

Veritabanı kavramının ilk kez 1980'li yıllarda ortaya atıldığı bilinmektedir. Veritabanları bir biriyle ilişkili verilerin depolandığı, kullanım amacına uygun olarak düzenlendiği mantıksal ve fiziksel olarak tanımlarının olduğu bilgi depolarıdır. Veritabanı sistemi, yeni bir veri tabanını düzenlemek, geliştirmek ve bakımını yapmak gibi çeşitli karmaşık işlemlerin gerçekleştirildiği birden fazla programı bünyesinde barındıran bir yazılım sistemidir (Alakoç,2005,s.12).

Genellikle veritabanları ücretsiz olarak hemen herkesin erişimine açık olan elektronik dergi ve veritabanları ile, herhangi bir kurum, kuruluş ya da yayınevi tarafından belirli bir süre için erişime açılan veritabanları, olmak üzere iki grup altında toplanmaktadır. 
Veritabanlarının güncellenme aralığının sık olması, güncel bilgi kaynaklarına erişimi mümkün kılmakta, tarama olanaklarının genişliği ile bilginin çok yönlü ve hızlı erişimine imkan vermekte ve çeşitli formatlardaki çıktı sunabilme kapasiteleriyle araştırmacılar tarafindan tercih edilmektedir. Ancak burada unutulmaması gereken veritabanı kullanımda gerekli olan bilgi okuryazarlığı becerilerinin varlığı ön koşul olarak ortaya çıkmaktadır (Rowley, 1996: 57).

Akademisyenler tarafından en çok kullanılan bibliyografik veri tabanlarını belirlemeye yönelik İsrail'de gerçekleştirilen bir araştırma sonucunda en çok kullanılan veri tabanının Web of Science (\% 47.3) olduğu, Web of Scince'ı, PubMed/MEDLINE' in da yer aldığı serbest erişimli diğer veri tabanları (\% 39.3) ve INSPEC 'in (\% 16.1) izlediği tespit edilmiştir (Bluma, Peritz ve Wolman, 2003: 352).

Sağlık bilimleri alanına yönelik Curtis, Weller ve Hurd (1993: 385-387), tıp, hemşirelik ve eczacılık alanındaki araştırmacıların en çok kullandığı veritabnını belirlemeye yönelik gerçekleş̧irilen bir diğer çalışmada, araştırmacıların \% 73.3'ü Index Medicus ya da MEDLINE, \% 35.5'i Current Contents ve \% 31,4 Science Citation Index veritabanını kullandığını belirtmiştir. 2003 yılında gerçekleştirilen bir diğer çalışmada, tıp fakültesi akademisyenlerinin en çok tercih ettiği veritabanı, MEDLİNE ve Web of Science olarak tespit edilmiştir (De Groote ve Dorsh, s. 2003: 236).

2013 yılında ülkemizde yapılmış bir diğer araştırmada, tıp fakültesi akademisyenlerinin veritabanı ve elektronik dergi kullanımları incelenmiştir. Araştırma sonucunda tıp fakültesi akademisyenlerinin \%87.4'ünün veritabanlarını ve elektronik dergi kullanımını, basılı koleksiyona tercih ettikleri belirlenmiştir (Doğan, 2013).

2007 yılında yapılan bir diğer çalışmaya göre akademisyenlerin \%67'si en az haftada bir gün veritabanlarını kullandıklarını belirtmişlerdir. 902 akademisyenin katıldığ 1 araştırmada, akademisyenlerin \%47'sinin bibliyografik veritabanlarını kullandığı sonucuna ulaşılmışır. Yine aynı çalışmaya göre akademisyenlerin alanlarıyla ilgili yeni yayınları takip etme ve güncel duyuru hizmeti alma konusunda veritabanlarını tercih ettikleri belirlenmiştir (Hemminger, Lu, Vaughan ve Adams, 2007).

Akademisyenlerin bilginin yeniden üretim serüveninde veritabanlarını oldukça sık kullandıklarını ortaya koyan bir diğer veri aşağıdaki tabloda yer almaktadır.

Tablo 3. Akademisyenlerin veritabanı kullanım sıklığı (Yaylı, Öztürk ve Alabay, 2003: 19).

\begin{tabular}{|c|c|c|c|c|c|c|c|c|c|c|c|}
\hline $\begin{array}{l}\text { Veritabanı } \\
\text { Adı }\end{array}$ & $\begin{array}{l}\text { Kull } \\
\text { rum }\end{array}$ & miyo & $\begin{array}{l}\text { Nad } \\
\text { kull } \\
\text { m }\end{array}$ & yoru & $\begin{array}{l}\text { Baze } \\
\text { kulla } \\
\text { um }\end{array}$ & lyor & $\begin{array}{l}\text { Hem } \\
\text { hem } \\
\text { çalss } \\
\text { kulla } \\
\text { m }\end{array}$ & $\begin{array}{l}\text { her } \\
\text { mda } \\
\text { yoru }\end{array}$ & $\begin{array}{l}\text { Her } \\
\text { çalıs } \\
\text { kull }\end{array}$ & Imda & Toplam \\
\hline $\begin{array}{l}\text { DEĞİSKEN } \\
\text { LER }\end{array}$ & $\mathbf{n}$ & $\%$ & $\mathbf{n}$ & $\%$ & $\mathbf{n}$ & $\%$ & $\mathbf{n}$ & $\%$ & $\mathrm{n}$ & $\%$ & n \\
\hline Ebscohost & 36 & 12,0 & 36 & 12,0 & 60 & 20,0 & 42 & 14,0 & 3 & 10,0 & 300 \\
\hline Proquest & 42 & 17,3 & 18 & 7,4 & 36 & 14,8 & 18 & 7,4 & 9 & 3,7 & 243 \\
\hline ScienceDirect & 36 & 11,8 & 36 & 11,8 & 57 & 18,6 & 69 & 22,5 & 57 & 18,6 & 306 \\
\hline $\begin{array}{l}\text { Web } \\
\text { Science }\end{array}$ & 45 & 16,9 & 30 & 11,2 & 63 & 23,6 & 36 & 13,5 & 30 & 11,2 & 267 \\
\hline Econlit & 45 & 20,0 & 21 & 9,3 & 21 & 9,3 & 9 & 4,0 & 9 & 4,0 & 225 \\
\hline $\begin{array}{l}\text { Science } \\
\text { Citation } \\
\text { Index }\end{array}$ & 39 & 14,0 & 48 & 17,4 & 60 & 21,7 & 45 & 16,3 & 27 & 9,8 & 276 \\
\hline Ulakbim & 45 & 15,0 & 42 & 14,0 & 81 & 27,0 & 51 & 17,0 & 36 & 12,0 & 300 \\
\hline Yök & 30 & 9,5 & 81 & 25,7 & 96 & 30,5 & 39 & 12,4 & 48 & 15,2 & 315 \\
\hline $\begin{array}{l}\text { Mesleki } \\
\text { veritabanlar1 }\end{array}$ & 30 & 10,0 & 45 & 15,0 & 81 & 27,0 & 42 & 14,0 & 51 & 17,0 & 300 \\
\hline
\end{tabular}

Tablodan da anlaşılacağı üzere akademisyenlerin büyük çoğunluğu herhangi bir veritabanı hakkında bilgi sahibi olmakla birlikte, araştırmalarında veritabanlarına erişim sağlamaktadır. 


\subsection{Elektronik Dergi}

Bilimsel iletişim açısından elektronik dergilerin öneminin her geçen gün arttı̆̆ 1 görülmektedir. 90'lı yılların başında 27 olarak belirlenen elektronik dergi sayısı 1999 yılına gelindiğinde 8000' e çıktı̆̆ görülmektedir. Ulrich's Periodical Directory veri tabanı üzerinde yapılan bir araştırmaya göre, 2005 yılındaki hakemli dergi sayıs1 16 binin üzerine çıkmıştır (Kurata, Matsubayashi, Mine, Muranushi ve Ueda, 2007,s. 1403; Kayaoğlu, 2004: 57). 2003 yilında Tennessee, Pittsburg ve Drexel Üniversitelerinde akademik personel ile akademik olmayan personelin bilimsel dergilerdeki makaleleri okuma eğilimleri üzerine yürütülmüş bir çalışmaya göre akademik personellerin bilimsel elektronik dergileri daha çok tercih etme eğiliminde oldukları belirlenmiştir (King, Tenopir ve Aerni, 2003: 3).

Bir diğer çalışmada bilimsel dergilerin önemi ve akademisyenlerin yılda ortalama kaç bilimsel makale okudukları incelenmiştir. Araştırma sonucunda 1993- 1998 yıllarını kapsayan süreçte ortalama 120 bilimsel makale okunurken, 2000-2001 kapsayan süreçte bu sayının 130'a çıktığı tespit edilmiş̧tir. Ayı araştırmada akademisyenlerin bilimsel içerikli makaleleri okumak için yılda ortalama 100 saatin üzerinde zaman ayırdıkları tespit edilmiştir. (Tenopir ve King, 2001:114).

Akademisyenlerin okudukları bilimsel makale sayıları üzerine gerçekleştirilen bir diğer çalışmada, okunan makale sayısının disiplinlere göre dağı̆lımı incelenmiş̧tir. Araştırma kapsamında mühendislerin, fizikçilerin, astronomların, kimyacıların ve tıp akademisyenlerinin yıllık ortalama okuduğu makale sayıları ve okumak için ayırdıkları süreler karşılaş̧ırılmıştır. Araştırma sonucunda tıp akademisyenlerinin yıllık 322 makale okuma ortalamasıyla diğer disiplinleri geride bıraktı̆̆ı tespit edilmiştir. Diğer yandan kimyacılar, fizikçiler ve astronomlar yıllık ortalama 107 saat ayırarak bilimsel makale okuduğu sonucuna ulaşılmıştır (Tenopir, King, Boyce, Grayson, 2005: 793-794).

Georgia Üniversitesi'nde gerçekleştirilen bir diğer çalışmada akademisyenlerin dergi kullanım oranları tespit edilmiştir. Buna göre temel ve sosyal bilimler alanındaki akademisyenlerin büyük çoğunluğu kendi abone oldukları dergileri kullanmayı tercih ederken (\%91), kütüphanenin abone olduğu basılı dergileri kullananların oranı (\%74) daha düşüktür. Elektronik dergi kullanımının disiplinlere göre dağllımına bakıldığında ise, temel bilimlerdeki akademisyenlerin, sosyal bilimlerdeki akademisyenlere nazaran daha fazla elektronik dergi kullandıkları tespit edilmiştir. Dergilere bireysel abonelik açısından temel bilimlerdeki akademisyenlerin oranı (\% 50), sosyal bilimlerdeki akademisyenlerin oranından (\%8) daha yüksek olduğu belirlenmiştir (Smith, 2003: 165166).

Akademisyenlerin okumak için kendi koleksiyonlarında yer alan bilgi kaynaklarının kaynakçalarından makale seçtikleri (\%55), bunun yanında bibliyografik veritabanlarını kullanarak (\%22) makalelere ulaştıkları saptanmıştır (Smith, 2003, s.166).

2003 yılında tıp alanındaki akademisyenlerin ve öğrencilerin örnekleme seçildiği bir diğer çalışmada, araştırmacıların \% 29'unun dergilerin basılı versiyonlarını; \% 71'inin ise elektronik versiyonlarını tercih ettiği ortaya çıkmıştır (De Groote, Dorsh,2003,s.234). örnekleme katılan basılı dergileri tercih eden araştırmacılar tercih nedeni olarak; "daha az sayfa harcandığını", "önemli yerlerin altını çizebiliyor olmalarını", "grafiklerin ve tabloların elektronik versiyona göre daha kaliteli olduğunu", "grafik ve tabloları okumanın daha kolay olduğunu" ve "fotokopi için beklenen sürenin elektronik versiyondan çıktı almak için beklenen süreden daha az olduğunu" belirtmişlerdir. Dergilerin elektronik versiyonunu tercih eden araştırmacılar ise, "maliyetin ucuz olması", "daha az zaman alması", "kütüphaneye gitmek zorunluluğunun ortadan kalkması", "çıktının daha hızlı alınabilmesi", "istenildiği zaman erişilebilmesi”, "kütüphanedeki basılı süreli yayın sayısının azlığı" gibi nedenler öne sürmüşlerdir.

\section{Değerlendirme ve Sonuç}

Bilgi erişim sistemlerinin ve buna paralel olarak bilgi merkezlerinin, bilginin yaşam döngüsündeki önemi her geçen gün artmaktadır. Sanal/dijital kültürün bilimsel amaçlı çalışmalara katkısı, arama motorlarından, veritabanlarından, çevrimiçi kataloglardan, bilimsel toplantı, konferans, bloglara kadar her alanda etkisi göz önündedir.

İnternetin hayatımıza girişiyle birlikte günümüzde, akademisyenler bilgi erişim sistemlerini bilimsel iletişim için kullanmaktadır. Bilgi erişim sistemlerinin bilgiye hızlı bir şekilde erişim ihtiyacı duyan akademisyenlerin bilgi arama davranışları üzerinde keskin bir etkisi olduğu söylemek mümkündür.

Günümüzde, bilgi arama davranışlarının üzerinde etkisini artırarak sürdüren bilgi erişim sistemlerinin, kullanıcılar tarafından etkin ve verimli kullanımına yönelik yürütülecek bilgilendirme çalışmalarına, eğitimlerine ve kullanımında karşılaşılan sorunların çözülmesinde bilgi merkezlerine ve bilgi erişim sistemi sağlayıcılarına önemli roller düşmektedir.

Konuyla ilgili olarak öneriler içerisine bilimsel bilgi kullanıcılarının bilgi arama davranışları ve elektronik kaynak kullanımları ilgili çalışmaların yapılması için araştırmacılar özendirilmeli, ortaya çıkan sonuçlar benzer çalışmalarla karşılaştırılarak benzerlik ve farklılıklar belirlenip, bu bilgiler ışı̆̆ında bilgi merkezleri ve bilgi 
merkezleri çalışanlarının paylaşımına sunulması gerekmektedir. Böylelikle elektronik bilgi kaynaklarının kullanım istatistiklerinin farklı kullanıcı gruplarına yönelik olarak tanımlanması ve akabinde elektronik koleksiyonun geliştirilmesi konusunda alınacak kararlar daha sağlıklı olacaktır.

Bilgi merkezlerinin kullanıcı ile bilgi sistemleri arasında etkin bir rol üstelenebilmesi için kullanıcısını ve bilgi arama davranışını yakından tanıması gerekmektedir. Bu doğrultuda bilgi merkezinin kullanııısı ile sürekli iletişim halinde olması, kullanıcısının hangi kaynaklara daha çok gereksinim duyduğunu belirlemesi yapılması gereken ilk basamağı oluşturmaktadır. Bilgi merkezi profesyonellerinin bilgi erişim sistemleri konusunda yetkin ve donanımlı olmasının bilginin yeniden üretim sürecinde etkili olacağı ve bağlı bulunduğu kurumun saygınlığa doğrudan etkisi olacağı unutulmamalıdır.

Elektronik bilgi kaynaklarının kullanım verilerinin ölçülmesi ve belirlenen verilerin bilgi merkezi çalışanları ile bilgi erişim sistemi sağlayıcılarıyla paylaşılması kaynakların efektif kullanımına doğrudan etki edecektir. Kullanıcıların bilgi arama davranışlarının belirlenmesi için; kullanııı merkezli çalışmalara gereksinim duyulmakta olup; kullanıcı merkezli çalışmalarda nicel ve nitel yöntemlerin bir arada yürütülmesi ile dinamik yapıdaki insan davranışlarına bir standart getirebileceğini unutulmamalıdır.

Bilgi erişim sistemleri araştırmacılar için, bilgiye erişimi kolaylaştırmakta ve araştırma sürecini kısaltmakta büyük bir avantaj sunmaktadır. Ülke genelinde bilimsel iletişim konusunda bilgi erişim sistemlerinin öneminin kavranmasına katkı sağlayacak, bununla birlikte elektronik yayıncılığın gelişmesi ve toplumun her kesimine ulaştırılması noktasında teknolojik ve ekonomik desteğe ihtiyaç söz konusudur. Ekonomik ve teknik alt yapıya ait sorunların ortadan kaldırılması elektronik ortamdaki bilgiye erişimi kolaylaştıracaktır. Bunun yanı sıra, bilgi merkezlerinin elektronik yayınlar konusunda kullanıcıyı işin içine dahil edeceği halkla ilişkiler çalışmaları ve kullanımı özendirecek uygulamalara gereksinim vardır.

\section{Kaynakça}

Alakoç, B. Z. (2005). Veri Tabanı Yönetim Sistemleri. Seçkin.

Atasoy, F.(2007). Kültürler Üzerinde Bilişim Devriminin Etkileri. Modern Türklük Araştırma Dergisi, 4(2), 163-178. Web: http://mtad.humanity.ankara.edu.tr/IV-2_Haziran/27_MTAD_4-2_FAtasoy_163-178.pdf 18 Aralık 2014 tarihinde erişildi.

Barry, C. A. (1995). Critical İssues in Evaluating the İmpact of IT on Information Activity in Academic i Research: Devoloping a Qualitative Research Solution. LISR, 17:107-134. Web: http://www.sciencedirect.com/science/article/pii/0740818895900179 04 Ocak 2015 tarihinde erişildi.

Bayer, A. E., Jahoda,G. (1981). Effect of Online Bibliographic Searching on Scientist'Information Style. Online Review,5: 4, 323- 333. Web: http://www.emeraldinsight.com/doi/pdfplus/10.1108/eb024068 05 Ocak 2015 tarihinde erişildi.

Bhat, S. V. R. ve Kumar, B. T. S. (2008). Web citation behaviour in scholarly electronic journals in the field of library and information science. Webology, 5(2). Web: http://www.webology.org/2008/v5n2/a57.html 05 Ocak 2015 tarihinde erişildi.

Bluma,J.B-I, Peritz, B.C. ve Wolman, Y. (2003). A Survey on the use of electronic databases and electronic journals accessed through the Israeli Universities. The Journal of Academic Librarianship 29 (6), 346 361.

Casebeer, L., Bennett, N., Kristofco, R., Carillo, A., \& Centor, R. (2002). Physician internet medical information seeking and on-line continuing education use patterns. Journal of Continuing Education in the Health Professions, 22(1), 33-42.

Curtis, K. L., Weller, A. C. ve Hurd, J. M. (1993). Information - seeking behavior of health sciences faculty: a survey of health sciences faculty use of indexes and databases. Bulletin of Medical Libraries Association, 81 (4), 383 - 392. 5 Ocak

2015 tarihinde PubMed Central veri tabanından erişildi. 
Davis, P. M. ve Cohen, S. A. (2001). The effect of the Web on undergraduate citation behavior 1996-1999. Journal of the American Society for Information Science and Technology, 52(4), 309-314. Web: http://onlinelibrary.wiley.com/doi/10.1002/1532-2890(2000)9999:9999\%3C::AIDASI1069\%3E3.0.CO;2-P/pdf 05 Ocak 2015 tarihinde erişildi.

De Groote, S. L. ve Dorsch, J. L. (2003). Measuring use patterns of online journals and databases. Journal of Medical Libraries Association, 91 (2), 231-240. 3 Ocak 2015 tarihinde PubMed Central veri tabanından erişildi.

Doğan, S. C. (2013). Tıp akademisyenlerinin elektronik veri tabanı ve elektronik dergi kullanımları: Hacettepe Üniversitesi örneği. http://bbytezarsivi.hacettepe.edu.tr/xmlui/handle/2062/255 adresinden erişildi.

Hemminger, B. M., Lu, D., Vaughan, K. T. L., \& Adams, S. J. (2007). Information seeking behavior of academic scientists. Journal of the American society for information science and technology, 58(14), 22052225.

Jankowska, M. A. (2004). Identifying University Professors Information Needs in the Challenging Environment of Information and Communication Technologies. The Journal of Academic Librarianship, 30, 1: 51-66.

Kayaoğlu, H.D. (2004). Bilimsel iletişim sürecinde basılı dergiden elektronik dergiye

geçiş. B. K. Ataman ve M. Yalvaç (Yay. Haz.), Aysel Yontar Armağanı içinde (ss.37-65). İstanbul: Türk Kütüphaneciler Derneği İstanbul Şubesi.

King, D. W., Tenopir, C., Montgomery, C. H. ve Aerni, S. E. (2003). Patterns of

journal use by faculty at three diverse universities. D-Lib Magazine, 9(10). Web: http://www.dlib.org/dlib/october03/king/10king.html 25 Aralık 2014 tarihinde erişildi.

Kurata, K, Matsubayashi, M, Mine, S. Muronushi, T, Ueda, S. (2007). Electronic

journals and their unbundled functions in scholarly communication: Views and utilization by scientific, technological and medical researchers in Japan. Information Processing \& Management, 43, 1402-1415.

Kurulgan, M.(2006). Bilgi Toplumunun Kütüphaneler Üzerine Etkisi. Web: http://kaynak.unak.org.tr/bildiri/unak05/u05-19.pdf 19 Aralık 2014 tarihinde erişildi.

Kushkowski, J. D. (2005). Web citation by graduate students: A comparison of print and electronic theses. Portal: Libraries and the Academy, 5(2), 259-276. Web: http://muse.jhu.edu/journals/pla/summary/v005/5.2kushkowski.html 05 Ocak 2014 tarihinde erişildi.

Smith, E. T. (2003). Changes in faculty reading behaviors: the impact of electronic journals on the University of Georgia. The Journal of Academic Librarianship, 29(3), $162-168$.

Tamdoğan, O. G. (2009). Enformasyon zincirinde bilgi erişim sistemleri, bilgi erişim sürecinde kütüphane kurumu ve diğer bilgi merkezleri. Türk Kütüphaneciliği, 23(1), 151-168.

Tamdoğan, O. G. (2009). Bilgi Üretiminde Yazın Ürünleri ve Kütüphaneler: Attfların Tespiti ve Analizi Yoluyla Araştırma. Türk Kütüphaneciliği, 23(2), 254-277.

Tanrıkulu, B. (2006). Akademisyen Mühendislerin Bilgi Arama Davranışlarına Bilgi Teknolojilerinin Etkisi: Bilkent Üniversitesi Örneği. Hacettepe Üniversitesi, Yüksek Lisans Tezi, Ankara.

Tenopir, C., King, D. W., Boyce, P., Grayyson, M ve Paulson, K. L. (2005). Relying

on electronic journals: reading patterns of astronomers. Journal of The American Society for Information Science and Technology. 56 (8), $786-802$. 
Tenopir, C. ve King,D. W. (2001). The use and value of scientific journals: past, present and future. Serials 14(2), 113-120.

Toffler, A. (2006). Gelecek Korkusu: Şok. İstanbul, Koridor Yayıncılık.

Tonta, Y. (2002). Elektronik Yayıncılık ve Elektronik Bilgi Kaynakları. Erişim tarihi, 01.12. 2014.

Tonta, Y. (2006). Kütüphaneler Sanal Güzergâhlara M1 Dönüşüyor?. Web: http://eprints.rclis.org/9430/1/tonta-istanbul-mayis-2006-bildiri.pdf 06 Ocak 2015 tarihinde erişildi.

Voorbij, H. ve Ongering, H. (2006). "The use of electronic journals by Dutch researchers: A descriptive and exploratory study," The Journal of Academic Librarianship, 32 (3): 223-237.

Yaylı, A. Öztürk, Y. ve Alabay, M. N. (2003). Türkiyedeki Akademisyenlerin İnterneti Kullanım Düzeylerini Belirlemeye Yönelik Bir Araştırma. Web: http://www.ttefdergi.gazi.edu.tr/makaleler/2003/Sayi2/259277.pdf 07 Ocak 2015 tarihinde erişildi.

Yılmaz, A. (2002). Hacettepe Üniversitesi İhsan Doğramacı Çocuk Hastanesi’nde Çalışan Hekimlerin Hasta Kayıt Sistemi Hakkındaki Düşünceleri ve Elektronik Hasta Kayıt Sisteminden Beklentileri. Bilim Uzmanlı̆̆ı Tezi, Hacettepe Üniversitesi Să̆lık Bilimleri Enstitüsü Sağlık Kurumları Yönetimi, Ankara. 